\title{
Multi-stage air gap membrane distillation reversal for hot impaired quality water treatment: Concept and simulation study
}

\author{
JungGil Lee ${ }^{1}$, Ahmad S. Alsaadi ${ }^{2}$, Noreddine Ghaffour ${ }^{*}$ \\ ${ }^{I}$ King Abdullah University of Science and Technology (KAUST), Water Desalination and Reuse Center (WDRC), \\ Biological and Environmental Science \& Engineering Division (BESE), Thuwal 23955-6900, Saudi Arabia, Tel. \\ +955-128082180,Email: noreddine.ghaffour@kaust.edu.sa \\ ${ }^{2}$ Chemical Engineering Department, University of Jeddah, Jeddah 21589, Saudi Arabia
}

\begin{abstract}
The major challenge of membrane distillation (MD) is the low gain output ratio (GOR) resulting from the high thermal energy requirement and the low water production. Here, the use of hot streams such as geothermal groundwater or produced water that are suitable to be treated by MD without the need for thermal energy input is discussed. Hot groundwater from the Northwest of Himalaya, India, is used as a case study. In this paper, we propose a novel multi stage air gap MD reversal design coupled with natural/forced cooling system. A 1-D rigorous simulation model is developed to estimate the performance of the proposed system. Water production capacity and GOR of various scenarios were estimated and reported. Based on our results, the increase in temperature difference between feed and brine discharge cooled down temperature can have a positive effect to improve both water production capacity and GOR. The increase of inlet feed flow rate increases the water production but not the GOR. The influence of increasing module width on water production and GOR is negligibly small. Results showed that the maximum GOR was about 3.89 without natural (passive) cooling system. Meanwhile, when natural $(90 \%)$ /forced (10\%) combined cooling system was applied, a GOR as high as 24.4 could be achieved.
\end{abstract}

Keywords: Desalination; AGMD efficiency; Hot feeds treatment; Multi-stage module; AGMD reversal; GOR.

\section{Introduction}


World water scarcity caused by global climate change continuously increases and it has a negative effect on the water quality and quantity due to the decrease in precipitation [1]. Moreover, the negative effect can be worse in remote areas where there is no desalination plants to produce fresh water. Large-scale mature desalination systems such as multi-stage flash (MSF), multi-effect desalination (MED) and reverse osmosis (RO), which can mitigate the water scarcity, are not economically suitable to be installed in such areas $[1,2]$. Therefore, a low footprint, small-scale and stand-alone desalination systems which can provide cost-effective fresh water may be demanded in the water market for mitigating water scarcity in those remote areas.

Membrane distillation (MD) process is considered as an alternative standalone emerging desalination system which is suitable for small-scale applications, requiring low footprint, and is easy to operate $[1,3]$. MD is a thermally driven separation process which uses the partial water vapor pressure difference as driving force which is yielded by the liquid/vapor interface on both feed and permeate membrane sides. A hydrophobic microporous membrane must be used in MD to prevent membrane wetting and allowing the transfer of water vapor only across its pores [4, 5]. The MD process is attractive as a next-generation desalination technology due to the following advantages [6-14]: (i) very high rejection rate for the non-volatile species present in feed solution, typically higher than $99.9 \%$ [10, 13, 15], (ii) low operation pressure [16], (iii) relatively low feed temperature compared to conventional thermal processes [10], and (iv) low sensitivity to salinity in feed solution and less exposed to fouling [13, 17]. In addition to these advantages, the required operating conditions of the MD process can make it possible to operate with small and less equipment compared to mature desalination systems.

There are different MD configurations, which are attractive for desalination application such as direct contact MD (DCMD), vacuum MD (VMD), air gap MD (AGMD), and material gap MD (MGMD) [18]. Among these configurations, AGMD has relatively lower heat conduction loss compared to DCMD. Additionally, it does not need an external condenser or a vacuum pump to drive the process [13]. The AGMD process can also generate and condense the water vapor simultaneously inside the module taking advantage of the latent heat of water vapor, thus it does not need an external heat exchanger for heat recovery $[17,19-21]$. These are the main advantages making AGMD configuration the first choice for process scale-up through pilot testing [19]. However, MD is still facing major challenges such as low water production and 
high specific thermal energy consumption. To overcome these issues, the application of multistage concept [1,22-31] and heat recovery [32-34] have been studied. Lee et al., [22] showed the dynamic performance of a solar-powered multi stage DCMD system according to the seasonal change in South Korea. They studied the importance of dynamically changed number of stages according to the available operating conditions resulted from the seasonal ambient temperature. In addition, the paper described the need for a multi-stage concept in detail. Khalifa et al., [23] built a real multi-stage AGMD system and conducted a comprehensive experimental study according to the various operating conditions and design parameters. The system performance in this study was also estimated and compared with the series and parallel configurations. Kim et al., [28] applied a multi-stage concept in a solar assisted DCMD system to increase the water production. Lee et al., [1] also presented a novel module design for the DCMD process with the multi-stage concept. They showed that although the mean permeate flux decreases with an increase in the total module length (number of stages), the water production increases due to the increase in the effective area. Lin et al., [32] presented an MD process coupled with heat exchanger for heat recovery. They reported that the implementation of heat exchanger on the MD process can achieve a high-cost and effective operation. Duong et al., [33] studied the performance of spiral-wound AGMD system for water treatment of RO brine from the coal seam gas (CSG) produced water. The AGMD module was designed to utilize the internal heat recovery of the system.

All the above researches have reported that the application of multi-stage concept and heat recovery can lead to an increase of the system's performance mainly water production and gain output ratio (GOR). But on the other hand, they agreed that in order to scale up the process the GOR value needs to be increased either through the reduction of thermal energy consumption or through increasing water production.

In this paper, a multi-stage AGMD reversal coupled with natural/forced cooling system is proposed to treat naturally hot feeds, such as hot springs, geothermal water or produced water. The concept consists of reversing the feed flow of a typical multi-stage AGMD system by supplying naturally hot feed water to the evaporators, and then a natural/forced cooling system is used after the last stage of evaporators to decrease the brine temperature by a few degrees to create and maintain a temperature difference between evaporation and condensation in all stages which represents the driving force of the process. The main advantage of the proposed system is that the 
cooling medium which could be supplied by ambient air or any impaired quality water available at ambient temperature using heat exchangers or cooling towers. Hot saline groundwater of the Northwest Himalaya, India, is used as a case study. The proposed system is featured to achieve a high GOR as it does not require heat input. Craig et al., [35] reported a groundwater temperature of $87^{\circ} \mathrm{C}$ with a discharged flow rate of $90 \mathrm{~L} / \mathrm{min}$ at Chumathang, Northwest Himalaya, India. They have also reported the various temperatures of groundwater available at various areas where there is a need for fresh water. Another example is in Riyadh, Saudi Arabia, where hot groundwater is cooled down in order to be treated by RO. MD could be a suitable and low-cost process of these types of low-enthalpy geothermal sources $[36,37]$. Therefore, we expect that the current proposed system could be a highly attractive alternative desalination system to provide fresh water at lowcost.

In remote areas where it is difficult to find cooling water resources, we propose the use of natural/forced cooling system to generate the driving force for separation (temperature difference between feed and brine discharge). In addition, if the thermal energy consumption of the forced cooling can be reduced by using natural (passive) cooling system, the GOR can be further increased. In this paper, we developed a rigorous one-dimensional AGMD model to estimate the performance of the proposed system at various scenario studies. Simulation results were validated with previously reported experimental data [20]. The proposed system performance is calculated and the obtained results were analyzed to find the key operating factors for improvement.

\section{System design}

\subsection{Multi-stage AGMD reversal system description}

Fig. 1 shows the schematic diagram of a typical multi-stage AGMD system (left in Fig.1) and the proposed multi-stage AGMD reversal system (right in Fig.1), and Fig. 2 presents the schematic of the AGMD module. The proposed multi stage AGMD reversal system which is coupled with natural/forced cooling system features the use of hot impaired quality water as feed solution. The natural cooling system is assumed to be operated under the infinity quantity of the cooling resource. In addition, the used solutions (i.e., air or water) are not recycled in the system in a one-through configuration. The multi-stage concept can enhance the heat recovery ratio and water production at the proper operating condtions, however, it can accompany the relatively high electrical energy for compensation of the pressure drop created along the channel as 
compared to shorter channel length.

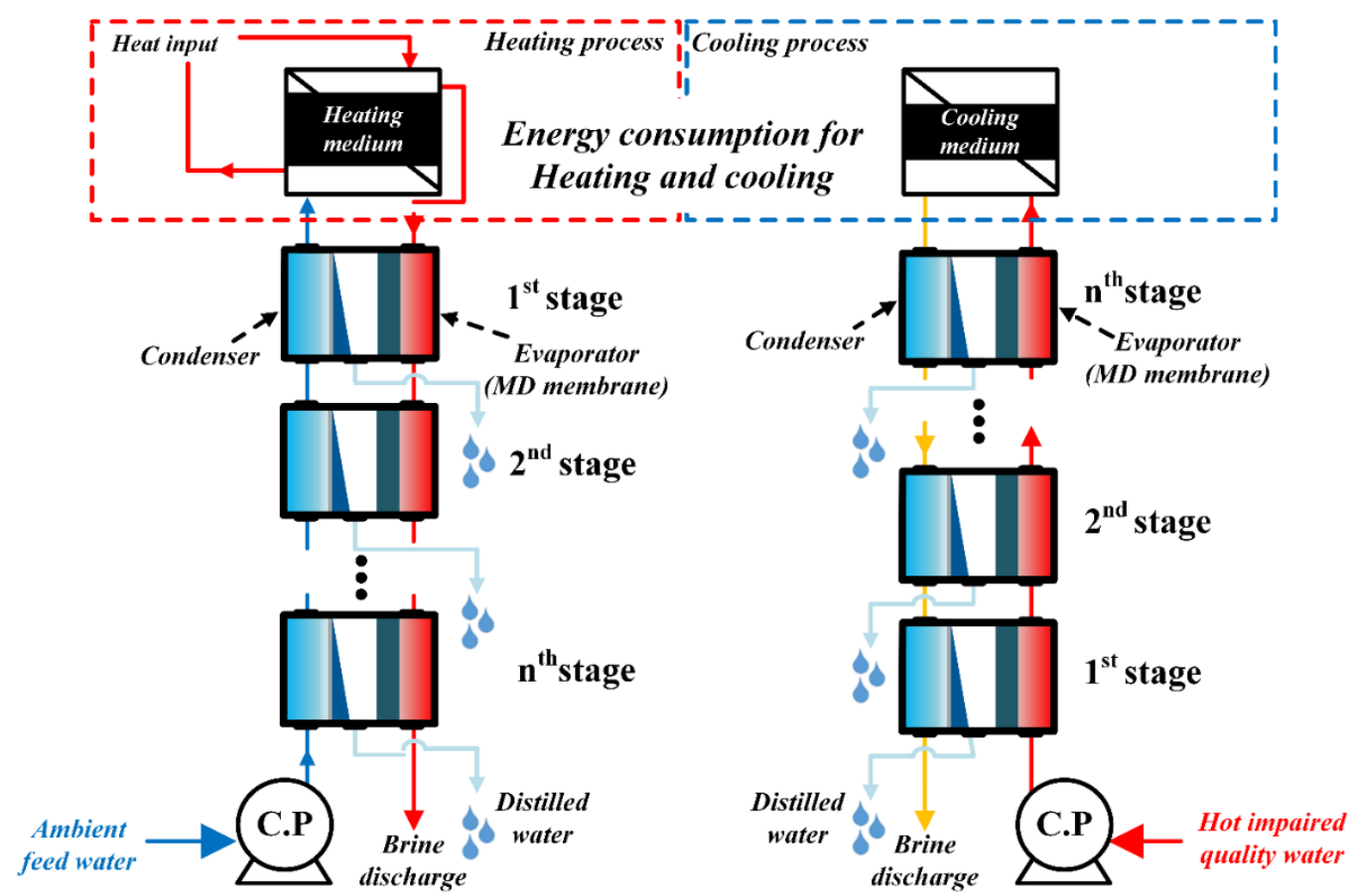

Figure 1. Schematic diagram of the typical multi-stage AGMD (left) and the proposed multistage AGMD reversal (right). Heating medium represents typical brine heater in thermal processes and cooling medium represents brine cooler.

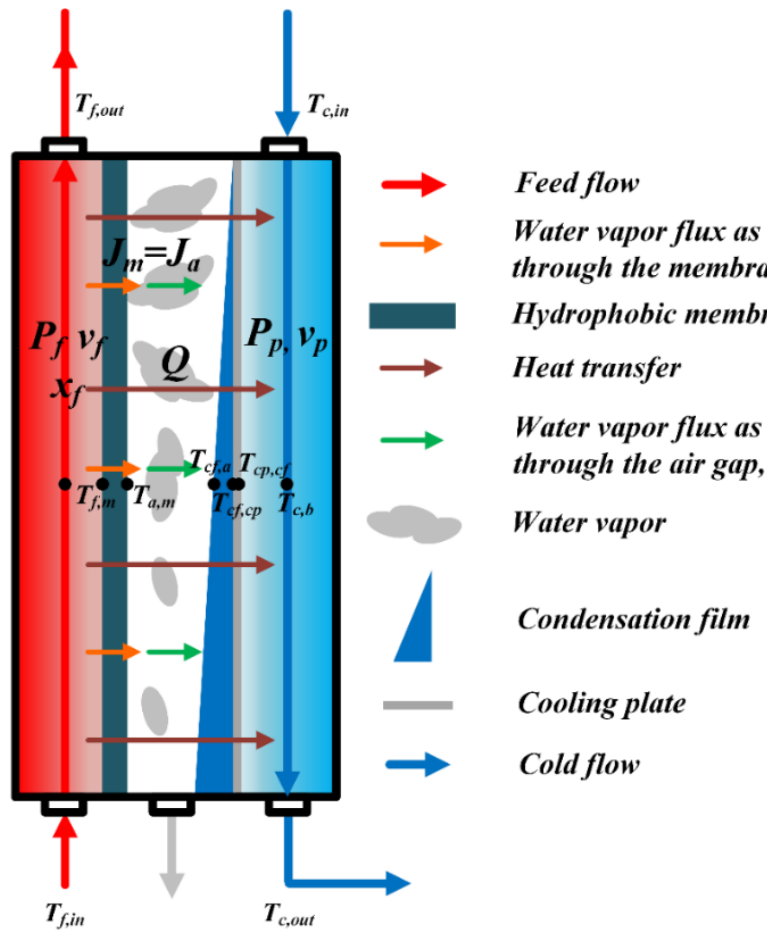

Figure 2. Schematic diagram of typical AGMD process. 
The driving force is created by using a cooling medium from the ambient, which makes the whole process operate at lower energy consumption [38]. These two systems (Fig. 1) are composed of AGMD modules, circulation pump, and heat exchanger (forced heating system for typical multi-stage AGMD and natural cooling system for multi-stage AGMD reversal), which is quite simple and easy to manufacture and operate compared to the conventional desalination systems. The use of heat exchangers create the temperature difference required for the separation by heating (typical AGMD) and cooling (AGMD reversal). In addition, both systems require thermal energy consumption for either heating or cooling which can be calculated through the following equation (the first law of thermodynamics).

$Q_{i}=\dot{m}_{\text {in }, H X} c_{p}\left|T_{f, \text { out }}-T_{c, \text { in }}\right|$

where $m_{i n, H X}$ is the volume flow rate at inlet cooling system, $c_{p}$ is the heat capacity, $T_{f, \text { out }}$ and $T_{c, \text { in }}$ are the outlet feed and inlet cold temperatures, respectively, and $\mathrm{Q}_{\mathrm{i}}$ is the quantity of heat (subscript of $i$ is heating or cooling). Dimensions of both feed and cold channels of each module are $5 \mathrm{~cm} \times 10 \mathrm{~cm} \times 0.2 \mathrm{~cm}$ (width $\times$ length $\times$ height). The air-gap employed in the AGMD module is $4 \mathrm{~mm}$. The operating procedure of the proposed system is as follows: (i) hot feed water is supplied to channel inlet by a circulation pump, (ii) water vapor which is generated at the liquid/vapor interface transfers across the membrane and the air-gap, (iii) water vapor transported is condensed on the condensation film on the cooling plate surface of the air-gap, and the condensation heat is recovered to cold side across the cooling plate at the same time, (iv) the feed outlet of the last stage is cooled down to the targeted inlet cold temperature $(\Delta T)$ by using the natural/forced cooling system or cooling tower and supplied to the cold inlet solution. The condensed distilled water is collected at each stage to prevent the growth of the condensation film thickness on the cooling plate surface of the air-gap. In this study, we assume that the generated water vapor can be fully condensed on the condensation film to recover the heat flux at the cold side.

\subsection{Membrane and spacer}

Commercial hydrophobic micro porous polytetrafluoroethylene (PTFE) membrane provided by 
Sterlitech Corporation was employed. The PTFE membrane manufactured by stretched manner was laminated on the scrim backing polypropylene (PP) structure. The pore size, $r_{m}$, porosity, $\varepsilon$, and thickness, $\delta_{m}$ of the membranes are $0.2 \mu \mathrm{m}, 80 \%$, and $100 \mu \mathrm{m}$, respectively [20]. The membrane contact angle measured was $160^{\circ}$. A PP spacer was used as a turbulence promoter [39-43]. The spacer can promote the turbulent flow from laminar flow and mitigate the temperature polarization and concentration polarization $[40,44,45]$. The filament thickness of the spacer $\left(\boldsymbol{d}_{\boldsymbol{f}}\right)$ is $0.4 \mathrm{~mm}$, the spacer thickness is $0.8 \mathrm{~mm}$, the mesh size $\left(\boldsymbol{l}_{\boldsymbol{m}}\right)$ is $2 \mathrm{~mm}$, and the attack angle of the spacer $(\boldsymbol{\theta})$ is $90^{\circ}$.

\section{Theoretical approach}

In this study, we developed a one-dimensional steady-state AGMD model to calculate the equations of heat and mass transfer and transportation behavior [1, 22, 25, 26, 46, 47] simultaneously and to improve the model accuracy. This is because the heat and mass transfer across the membrane and transportation behavior in both duct channels are linked at the same time in the MD process. The assumptions for the simulation study are as follows: (i) steady incompressible flow, (ii) negligible heat loss to the atmosphere, (iii) frictionless in the chennel module with flows, and (iv) water vapor is fully condensed on the cooling plate.

\subsection{Mass transfer}

(i) Mass transfer across the hydrophobic membrane

The permeability of the hydrophobic membrane can be calculated by the dusty gas model. In the AGMD process, the transient diffusion which consists of Knudsen and Molecular diffusion are dominantly controlling the mass transfer across the membrane $[13,20]$, it can be expressed as:

$$
J_{\text {mem }}=C_{m}\left(P_{f, m}-P_{a, m}\right)
$$

where $p_{f, m}$ and $p_{a, m}$ are the partial vapor pressure on the liquid/vapor interface of feed and air-gap sides, respectively, and $C_{m}$ is the overall mass transfer coefficient (MTC) across the membrane.

$C_{m}=\left(R_{K}+R_{M}\right)^{-1}$ where, $R_{K}^{-1}=C_{K}\left(M_{w} / R T_{m}\right)^{0.5}, R_{M}^{-1}=C_{M}\left(D M_{w} / P_{a M} R T_{m}\right)$

where $C_{K}=r \varepsilon / \tau \delta$ and $C_{M}=\varepsilon / \tau \delta$ which are structural parameters for Knudsen and Molecular diffusion, respectively, $P_{a M}$ is the log-mean air pressure at both sides of the membrane, and $P_{m}$ is the mean water vapor pressure inside the membrane, $M_{w}$ is the molecular weight of water, $R$ is 
the ideal gas constant, $T_{m}$ is the average transmembrane temperature, and $D$ is the binary diffusion coefficient.

(ii) Mass transfer across the air-gap

The mass transfer as water vapor across the air-gap can be expressed as:

$J_{a}=C_{a}\left(P_{a, m}-P_{c f, a}\right)$

where $p_{c f, a}$ is the vapor pressure on the air gap side of the condensation film, and $C_{a}$ is the MTC of the stagnant air contribution in the air gap area.

$C_{a}=\frac{D_{v / a} M_{w} P_{0}}{\delta_{g} P_{a M g} T_{g}}$

where $D_{v / a}$ is the diffusion coefficient of the mixture of dry air and water vapor, $\delta_{g}$ is the air gap thickness, and $T_{g}$ is the air gap temperature.

The overall water vapor flux, $J_{o}$ can be expressed based on the mass balance as follows:

$J_{o}=J_{m}=J_{a}$

Combining Eqs. (1)-(5) gives:

$J_{o}=\left(\mathrm{C}_{m}^{-1}+\mathrm{C}_{a}^{-1}\right)^{-1}\left(p_{f, \mathrm{~m}}-p_{c f, a}\right)$

The mean water vapor flux $\left(J_{m}, \mathrm{~kg} / \mathrm{m}^{2} \mathrm{~h}\right)$ and water production $\left(W_{P}, \mathrm{~kg} / \mathrm{h}\right)$ can be calculated by the following equations, respectively.

$$
\begin{aligned}
& J_{m}=\frac{1}{L} \int_{0}^{L} J_{o}(z) d z \\
& W_{p}=\int_{0}^{L} J_{o}(z) d z
\end{aligned}
$$

\subsection{Heat transfer}

In this study, spacers were employed at both feed and cold sides to promote the flow pattern from laminar to turbulent. Therefore, the modified equations of hydraulic diameter and Nusselt number used in this study were employed, refer to [20, 40]. In the AGMD process, the heat transfer from the bulk feed to the bulk coolant can be expressed as follows:

(i) Heat transfer between bulk feed and liquid/vapor interface at the miniscus of the membrane. 
$Q_{f}=h_{f}\left(T_{f, b}-T_{f, m}\right)$

$N u_{f, c}=h_{f, c} d_{h, s p} / k=0.023 k_{d c} \operatorname{Re}^{0.8} \operatorname{Pr}^{n}, \mathrm{n}=0.4$ for heating and $\mathrm{n}=0.3$ for cooling.

where $l$ is the module length, $k_{d c}$ is the spacer factor [40,44], $T_{f, b}$ is the bulk feed temperature, $T_{f, m}$ is the feed transmembrane temperature, $h_{f, c}$ is the convection heat transfer coefficients of the feed (f) and cold (c) flows, and $d_{h, s p}$ is the modified hydraulic diameter due to the implementation of spacers $[40,44]$.

(ii) Heat transfer across the membrane

$Q_{m}=J_{o} \Delta H_{g}+\frac{k}{\delta_{m}}\left(T_{f, m}-T_{a, m}\right)$

where $\Delta H_{g}$ is the enthalpy of water vapor, $k=\varepsilon k_{\text {air }}+(1-\varepsilon) k_{m}, k_{\text {air }}$ and $k_{m}$ are the thermal conductivity of air and membrane material, respectively, and $T_{a, m}$ is the transmembrane temperature of the air gap side.

(iii) Heat transfer across the air gap

$$
Q_{a}=J_{o} \Delta H_{g}+\frac{k_{v / a}}{\delta_{a}}\left(T_{a, m}-T_{c f, a}\right)
$$

where $k_{v / a}$ is the thermal conductivity in the gas mixture of air and water vapor, $\delta_{a}$ is the thickness of the air gap, and $T_{c f, a}$ is the surface temperature of condensation film at the air gap side.

Combing (ii) and (iii), we get:

$Q_{m_{-} a}=J_{o} \Delta H_{g}+\frac{1}{\left(k / \delta_{m}\right)^{-1}+\left(k_{v / a} / \delta_{a}\right)^{-1}}\left(T_{f, m}-T_{c f, a}\right)$

(iv) Heat transfer across the condensation film

$$
Q_{\text {cond }}=\frac{k_{\text {cond }}}{\delta_{\text {cond }}}\left(T_{c f, a}-T_{c f, c p}\right)
$$

where $k_{\text {cond }}$ is the thermal conductivity of the condensation film, $\delta_{\text {cond }}$ is the thickness of the condensation film $[20,48]$, and $T_{c f, c p}$ is the film temperature in contact with the cooling plate.

(v) Heat transfer across the cooling plate 
$Q_{c p}=\frac{k_{c p}}{\delta_{c p}}\left(T_{c f, c p}-T_{c p, c f}\right)$

where $k_{c p}$ is the thermal conductivity of the cooling plate, $\delta_{c p}$ is the thickness of the cooling plate, and $T_{c p, c f}$ is the temperature of the cooling plate surface in the coolant channel.

(vi) Heat transfer between cooling plate surface on cold side of the membrane and bulk cold side

$Q_{c}=h_{c}\left(T_{c p, c f}-T_{c, b}\right)$

where $T_{c, b}$ is the bulk coolant temperature.

Rearranging (iv), (v), and (vi) result in:

$Q_{\text {cond }, c p, c}=\frac{1}{\left(k_{\text {cond }} / \delta_{\text {cond }}\right)^{-1}+\left(k_{c p} / \delta_{c p}\right)^{-1}+\left(1 / h_{c}\right)^{-1}}\left(T_{c f, a}-T_{c, b}\right)$

\subsection{Transport behavior}

The transport behavior in feed side which is coupled by the differential equations such as the momentum, mass, species and energy balances can be expressed as follows:

$\frac{d P_{f}}{d z}=-\frac{3 \mu_{f}}{h_{c}^{2}} v_{f}$

$\frac{1}{M_{v, f}} \frac{d v_{f}}{d z}-\frac{v_{f}}{M_{v, f}^{2}}\left(\frac{M_{s}}{\rho_{s}}-\frac{M_{w}}{\rho_{w}}\right) \frac{d x_{f}}{d z}=-\frac{J}{M_{f} \varepsilon_{s p} h_{c}}$

$\frac{x_{f}}{M_{v, f}} \frac{d v_{f}}{d z}+\frac{v_{f} M_{w}}{\rho_{w} M_{v, f}^{2}} \frac{d x_{f}}{d z}=0$

$\frac{d \rho_{f} v_{f} c_{p, f} T_{f, b}}{d z}=-\frac{Q_{f}}{\varepsilon_{s p} h_{c}}$

where $P_{f}$ is the feed bulk pressure, $v_{f}$ is the feed velocity, $x_{f}$ is the feed salinity, $T_{f, b}$ is the bulk feed temperature, $d z$ is the grid size for module length, $\mu_{f}$ is the dynamic viscosity, $h_{c}$ is the channel height, $\rho_{f}$ is the bulk feed density, $M_{s}$ is the molecular weight of salt, $M_{v, f}$ is the molar volume of feed solution, $c_{p, f}$ is the specific heat of feed solution, and $\varepsilon_{s p}$ is the spacer porosity $[40,44]$.

The boundary conditions for the transport behavior at the feed flow can be expressed as follow:

$P_{f}(0)=P_{0}, v_{f}(0)=v_{f, i n}=\frac{V_{f, i n}}{\varepsilon_{s p} h_{c} w_{c}}, x_{f}(0)=x_{f, i n}, T_{f}(0)=T_{f, b, i n}$

where $V_{f, i n}$ is the inlet flow rate of the feed side. 
In AGMD, the condensed distilled water is perfectly separated with cold side. Thus, in the permeate side, the transport behavior which is coupled by the differential equations such as the momentum and energy balances can be described as follows:

$$
\begin{aligned}
& \frac{d P_{c}}{d z}=-\frac{3 \mu_{c}}{h_{c}^{2}} v_{c} \\
& \frac{d \rho_{c} v_{c} c_{p, c} T_{c, b}}{d z}=-\frac{Q_{c}}{\varepsilon_{s p} h_{c}}
\end{aligned}
$$

where $P_{c}$ is the coolant bulk pressure, $v_{c}$ is the coolant velocity, $T_{c, b}$ is the coolant temperature, $\rho_{c}$ is the bulk coolant density, and $c_{p, c}$ is the specific heat of the coolant.

The boundary conditions for the transport behavior at the coolant flow rate can be expressed as follows:

$$
P_{c}(0)=P_{0}, v_{c}(L)=v_{f, \text { out }}=\frac{V_{\mathrm{f}, \text { out }}}{\varepsilon_{s p} h_{c} w_{c}}, T_{c}(L)=T_{c, b, \text { in }}
$$

where $V_{f, \text { out }}$ is the outlet flow rate of cold side and $w_{c}$ is the module width.

The gain output ratio (GOR) can be calculated by:

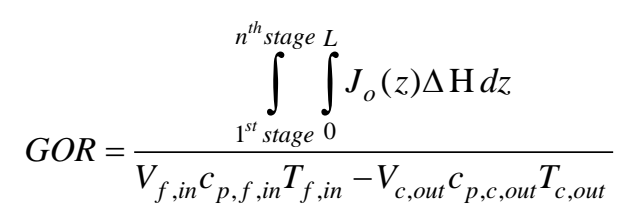

where $V_{c, \text { out }}$ is the outlet flow rate of a cold side at the first stage which has lost the freshwater due to the water vapor generation at the feed side.

Water recovery can be expressed by:

$W R(\%)=\frac{\text { Water prodcution }(\mathrm{kg} / \mathrm{min})}{\text { Inlet Flow rate }(\mathrm{kg} / \mathrm{min})} \times 100$

\subsection{Solution procedure and model validation}

The finite volume method was employed to discretize the set of coupled ordinary differential equations for both feed side (Eqs. (18)-(21)) and coolant side (Eqs. (22)-(23)) as transportation behavior in the duct channel. The set of coupled ordinary differential equations for both feed and coolant sides are solved simultaneously with heat (Eqs. (10)-(17)) and mass transfer (Eqs. (2)- 
(7)). Broyden's method is employed to solve the theoretical AGMD simulation model. The inlet coolant flow rates were estimated by the iteration method according to the scenarios (Fig. 3).

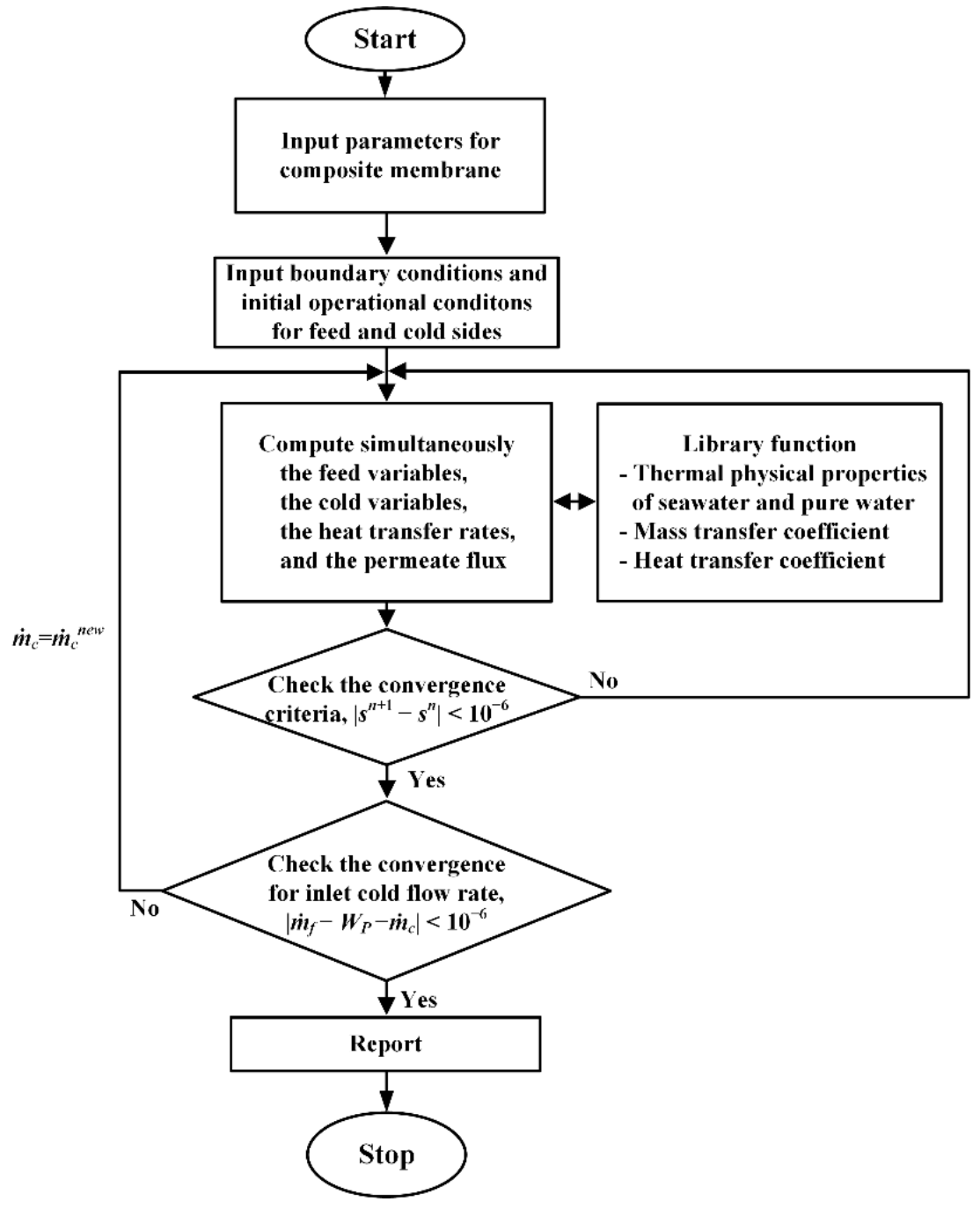

Figure 3. Diagram of the solution procedure.

Fig. 4 shows the effect of inlet feed temperature on the water vapor flux (measured and simulated) for (a) deionized water and (b) Red Sea water as feed solution. The model predictions are in good agreement with the measured results, reported elsewhere [20]. The simulated results of Red Sea water were slightly higher than the experimental results, most probably due to scaling/fouling [49]. 


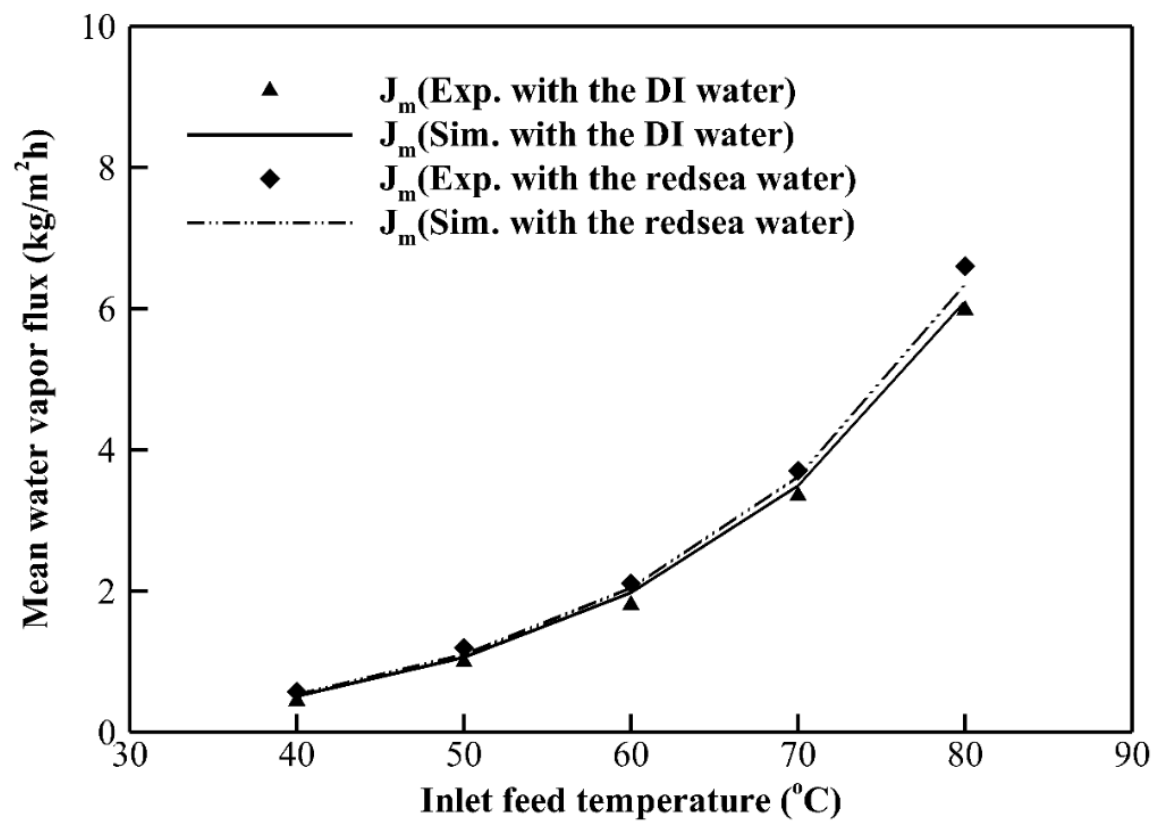

Figure 4. Effect of inlet feed temperature on the water vapor flux (measured and simulated) for deionized water and Red Sea water as feed solution.

\section{Scenarios matrix}

Table. 1 Scenarios matrix

\begin{tabular}{cll}
\hline No. & Cases & Variables \\
\hline 1 & Coolant inlet temperature & $40^{\circ} \mathrm{C}, 45^{\circ} \mathrm{C}$ and $50^{\circ} \mathrm{C}$ \\
2.1 & Inlet feed temperature & $60^{\circ} \mathrm{C}, 70^{\circ} \mathrm{C}, 80^{\circ} \mathrm{C}$ and $90^{\circ} \mathrm{C}$ \\
2.2 & $\begin{array}{l}20^{\circ} \mathrm{C} \text { of temperature difference } \\
\text { between feed inlet and brine }\end{array}$ & $70^{\circ} \mathrm{C}, 80^{\circ} \mathrm{C}$ and $90^{\circ} \mathrm{C}$ \\
& $\begin{array}{l}\text { discharge } \\
3\end{array} \quad$ Inlet flow rate & $1.0 \mathrm{~kg} / \mathrm{min}$ to $3.0 \mathrm{~kg} / \mathrm{min}$ \\
4 & Feed/coolant channel widths & $5 \mathrm{~cm}, 7.5 \mathrm{~cm}$, and $10 \mathrm{~cm}$ \\
\hline${ }^{*} 5 \mathrm{~cm} \times 10 \mathrm{~cm} \times 0.02 \mathrm{~cm}$ (width $\times$ lenght $\times$ height).
\end{tabular}

Various scenario studies (Table 1) were conducted to estimate the performance of the proposed system such as water production and GOR. In all scenarios, the maximum required module length applied was determined by considering the temperature difference between feed inlet and coolant outlet to achieve around $10^{\circ} \mathrm{C}$ according to the scenarios.

\section{Results and discussion}



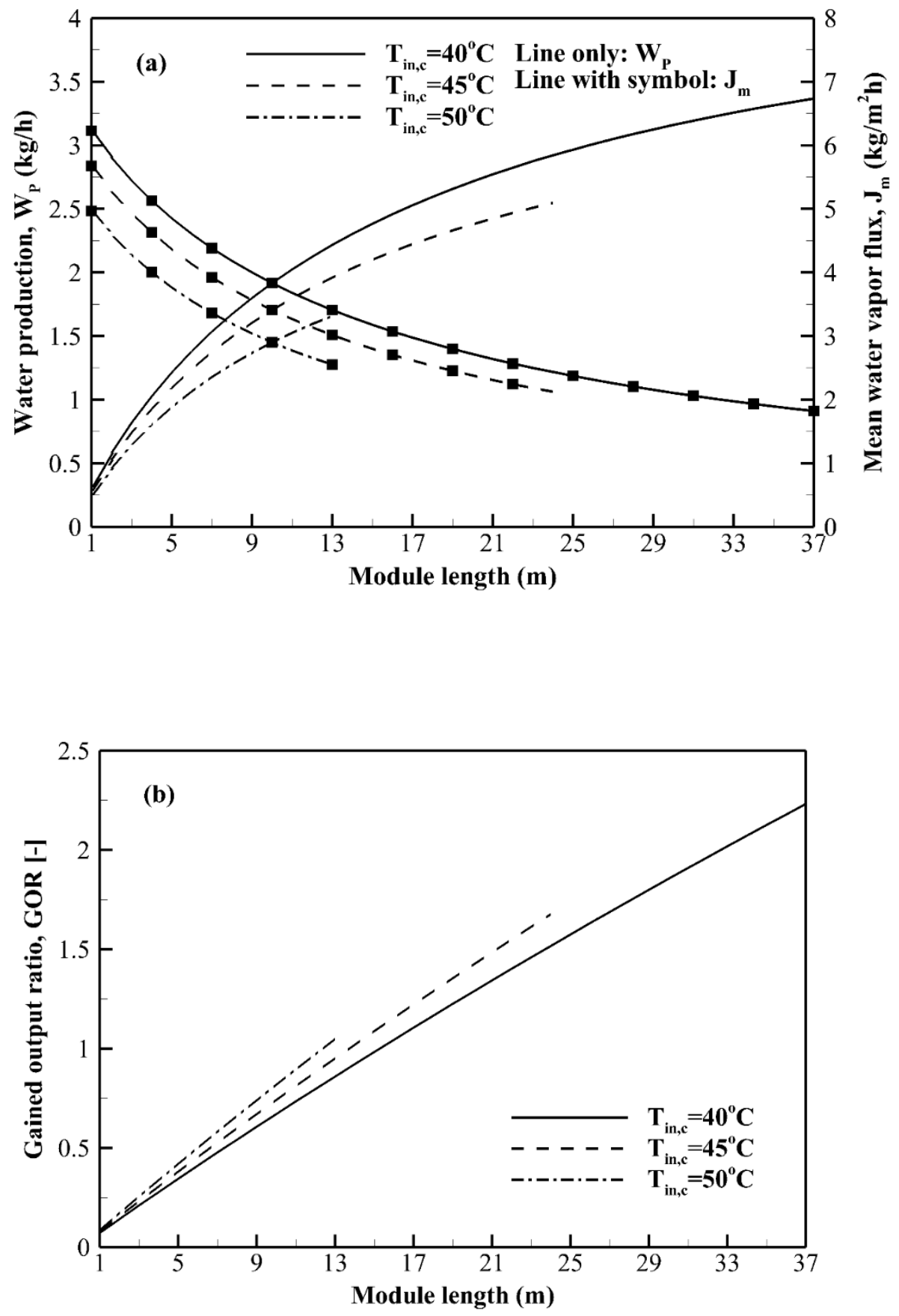

Figure 5. Influence of coolant inlet temperature on (a) water production and mean water vapor flux, and (b) GOR at $70^{\circ} \mathrm{C}$ (inlet feed temperature), $1.5 \mathrm{~kg} / \mathrm{min}$ (inlet feed flow rate), and $42 \mathrm{~g} / \mathrm{kg}$ (feed salinity). 
Fig. 5 shows the effect of coolant inlet temperature on (a) the water production and mean water vapor flux, and (b) the GOR at inlet feed temperature of $70^{\circ} \mathrm{C}$ (as an example of available natural hot source), inlet feed flow rate of $1.5 \mathrm{~kg} / \mathrm{min}$, and feed water salinity of $42 \mathrm{~g} / \mathrm{kg}$. The mean water vapor flux and water production increase with a decrease in the coolant inlet temperature due to the increase of the driving force. However, the mean water vapor flux decreases as the module length increases. This is because the temperature difference between feed and coolant sides decreases as the module length (effective area) increases. In addition, it can be decreased further with an increase in the module length due to its counter-current flow circulation. The water production increases also with the decrease in the coolant inlet temperature due to the increase in the driving force as well as with the increase in the effective area, as shown in Fig. 5(a). These results are in good agreement with previous simulation and experimental results $[1,20,50]$. The maximum water recovery is about $3.74 \%$ at inlet feed and coolant temperatures of $70^{\circ} \mathrm{C}$ and $40^{\circ} \mathrm{C}$, respectively, inlet feed flow rate of $1.5 \mathrm{~kg} / \mathrm{min}$, and feed salinity of $42 \mathrm{~g} / \mathrm{kg}$.

In this study, the forced cooling thermal energy is calculated by using Eq. (1). As shown in Fig. 6, the maximum GOR increases from 1 to 2.23 as the coolant inlet temperature decreases from $50^{\circ} \mathrm{C}$ to $40^{\circ} \mathrm{C}$. However, the maximum module length which is required to achieve the $10^{\circ} \mathrm{C}$ temperature difference between feed inlet and coolant outlets as heat recovery increases with an increase in the coolant inlet temperature. The GOR as a result of the lower temperature difference is slightly higher than that as a result of the higher temperature difference at the same module length, as shown in Fig. 5(b). This is because the higher temperature difference between feed inlet and coolant outlet can lead to higher conduction heat loss. The increase in the conduction heat loss reduces the available thermal energy for water evaporation and generation. However, the higher the temperature difference between feed inlet and coolant outlet can lead to higher water production and higher GOR through the heat recovery.

As shown in Fig. 6, we applied the $37 \mathrm{~m}$ as total module length, which may seem too long for practical application, however this module length is necessary to fully recover the heat. Such module length could be achieved in a small footprint by using specific module designs, e.g. discs with sinusoidal flow). Even though the transmembrane temperature difference is almost the same along the module length, the water vapor flux which has a latent heat, decreases exponentially according to water vapor liquid equilibrium (vapor pressure vs. temperature curve). Therefore, the required total module length can be increased by increasing the temperature difference between 
feed inlet and coolant outlet, (increase in the inlet feed flow rate or decrease in the module width).

\subsection{Influence of inlet feed temperature (in the range of possible natural hot sources)}
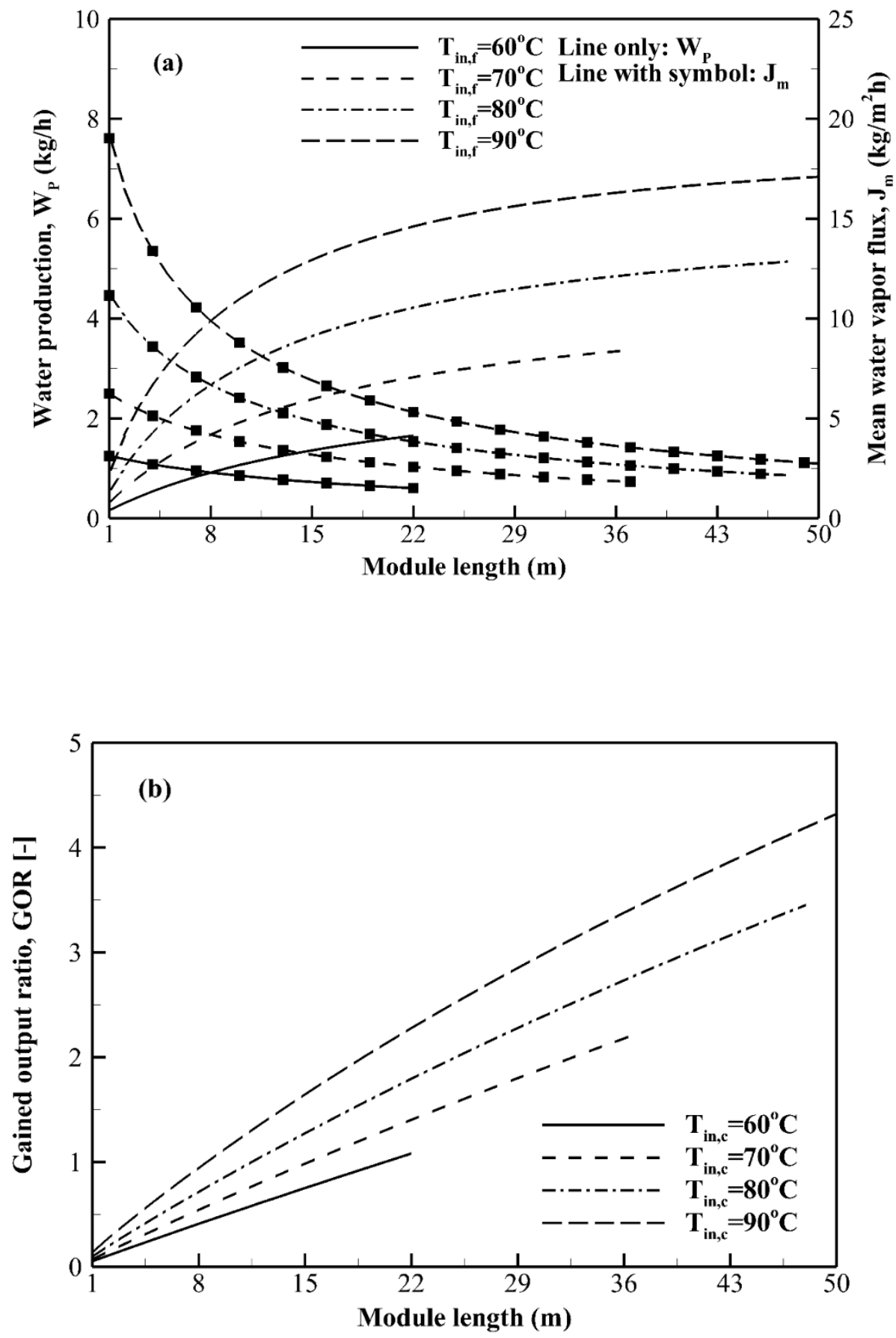

Figure 6. Effect of inlet feed temperature on (a) water production and mean water vapor flux, 
and (b) GOR at $40^{\circ} \mathrm{C}$ (coolant inlet temperature, controlled by the cooling medium), $1.5 \mathrm{~kg} / \mathrm{min}$ (inlet feed flow rate), and $42 \mathrm{~g} / \mathrm{kg}$ (feed salinity).

As shown in Fig. 6(a), the mean water vapor flux and water production increase as the inlet feed temperature increases. This is because the partial water vapor pressure increases exponentially as inlet feed temperature increases, and hence the driving force is higher. The possible water production asymtotically increases as the total moduel length increases. Although the partial vapor pressure of the inlet feed increases, the transmembrane temperature difference decreases due to the increase in the module length (effective area) at a certain optimum [51]. The maximum water recovery is about $7.59 \%$ at inlet feed and coolant temperatures of $90^{\circ} \mathrm{C}$ of $40^{\circ} \mathrm{C}$, respectively, inlet feed flow rate of $1.5 \mathrm{~kg} / \mathrm{min}$, and feed salinity of $42 \mathrm{~g} / \mathrm{kg}$.

Fig. 6(b) shows the effect of inlet feed temperatures on the GOR. At a feed inlet temperature of $90^{\circ} \mathrm{C}$, the maximum achieved GOR is 4.32 for a long module of $50 \mathrm{~m}$. It also shows that, based on the higher water production, the GOR can be increased greatly through an efficient heat recovery.

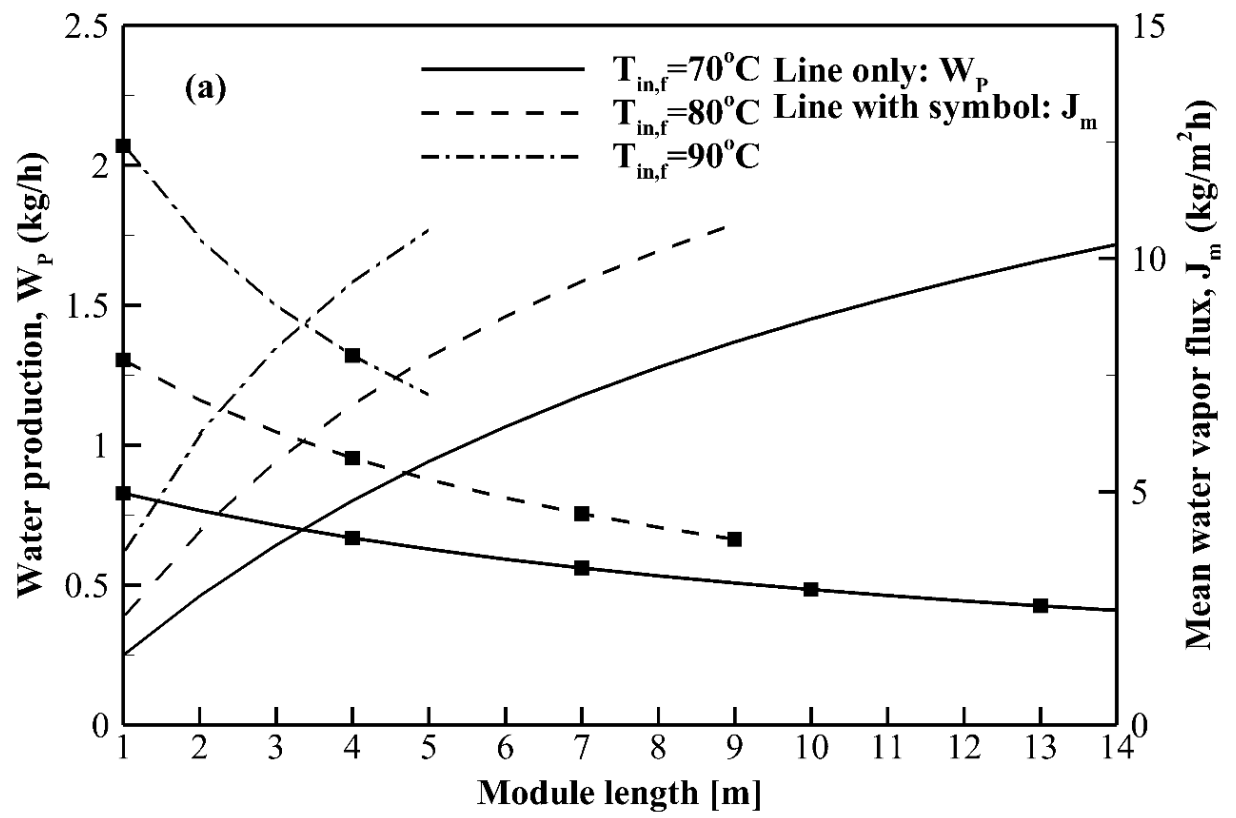




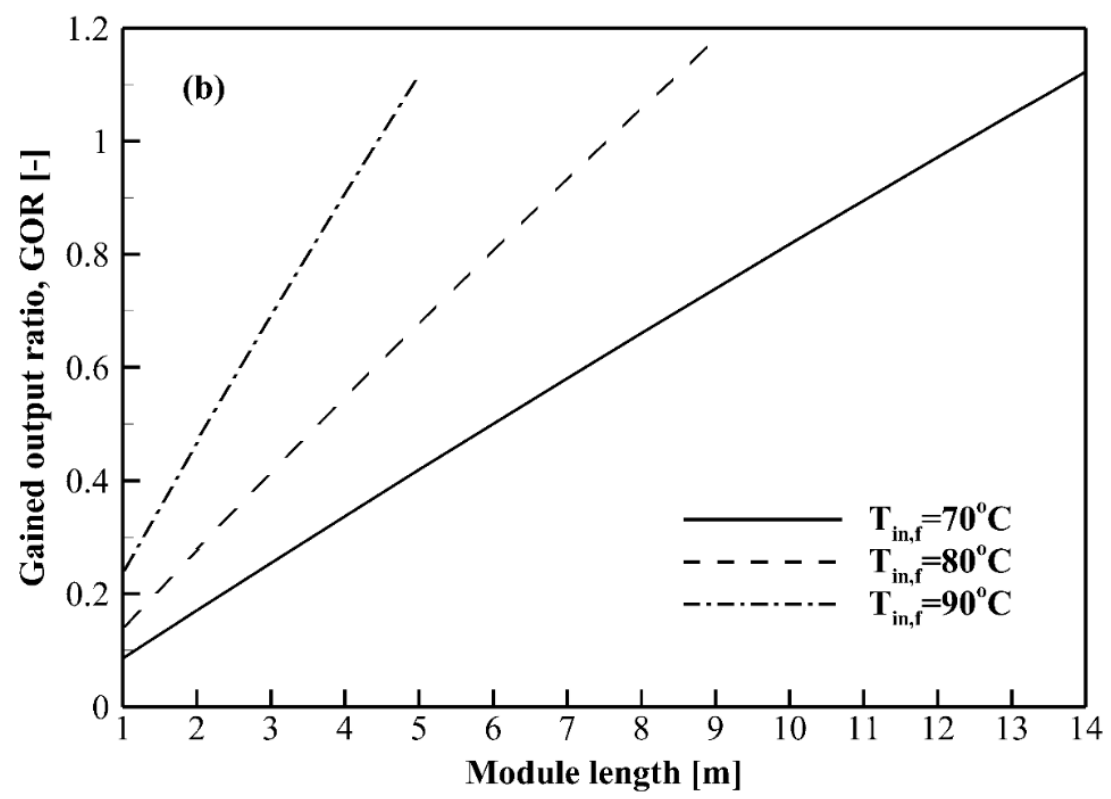

Figure 7. Influence of various inlet feed temperatures on (a) water production and mean water vapor flux, and (b) GOR at $1.5 \mathrm{~kg} / \mathrm{min}$ (inlet feed flow rate), $\Delta \mathrm{T}=20^{\circ} \mathrm{C}$ (temperature difference between feed inlet and coolant outlet), and $42 \mathrm{~g} / \mathrm{kg}$ (feed salinity).

When various inlet feed temperatures $\left(70^{\circ} \mathrm{C}, 80^{\circ} \mathrm{C}\right.$, and $\left.90^{\circ} \mathrm{C}\right)$ at a temperature difference of $\Delta \mathrm{T}=20^{\circ} \mathrm{C}$ are used, the maximum water production and GOR do not show significant difference (Fig. 7(a) and (b)). The maximum water recovery is 7.86\% at inlet feed and coolant temperatures of $90^{\circ} \mathrm{C}$ and $40^{\circ} \mathrm{C}$, respectively, inlet feed flow rate of $1.5 \mathrm{~kg} / \mathrm{min}$, and feed salinity of $42 \mathrm{~g} / \mathrm{kg}$. But this value was not significantly different when compared to the water recovery obtained at feed inlet temperatures of $70^{\circ} \mathrm{C}$ and $80^{\circ} \mathrm{C}$. However, higher inlet feed temperature can reduce the required effective membrane area due to the higher mean water vapor flux.

\subsection{Influence of inlet feed flow rate}



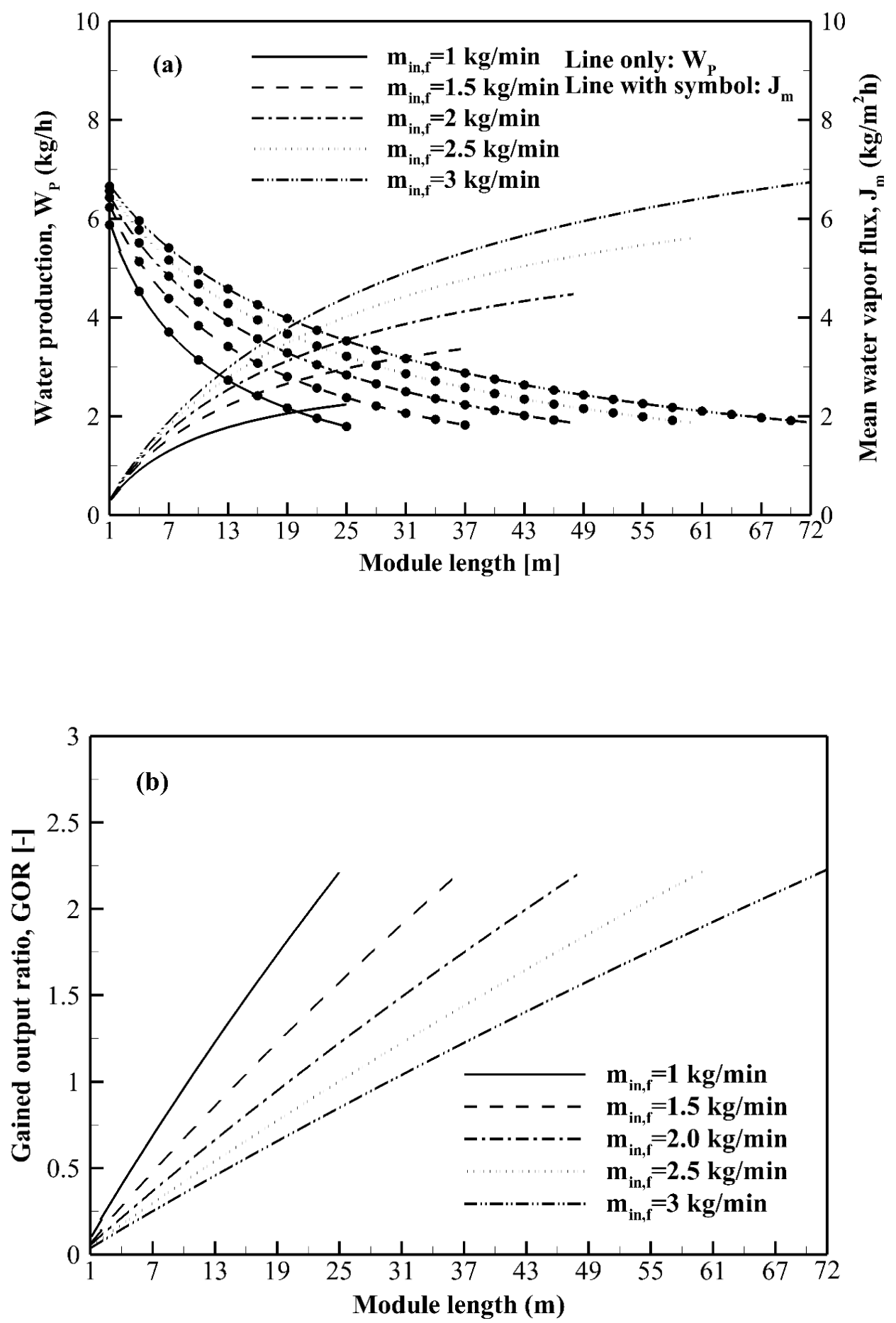

Figure 8. Effect of inlet feed flow rate on (a) water production and mean water vapor flux, and (b) GOR at $70^{\circ} \mathrm{C}$ and $40^{\circ} \mathrm{C}$ (inlet feed and cold temperatures, respectively), and $42 \mathrm{~g} / \mathrm{kg}$ (feed salinity). 
With a fixed channel area, the higher inlet flow rate can lead to higher inlet feed velocity (Fig. 8 (a)). The mean water vapor flux and water production increase as the inlet feed flow rate increases. This is because the increase in the flow rate can improve the Reynolds number which is the ratio of inertial forces to viscous forces and hence the convective heat transfer, and also can reduce the residence time in the channel. The enhanced convective heat transfer can reduce temperature polarization, which is a major challenge in the MD process. Furthermore, the maximum water recovery is $7.48 \%$ at inlet feed and cold temperatures of $70^{\circ} \mathrm{C}$ and $40^{\circ} \mathrm{C}$, respectively, inlet feed flow rate of $3.0 \mathrm{~kg} / \mathrm{min}$, and feed salinity of $42 \mathrm{~g} / \mathrm{kg}$.

As shown in Fig. 8(b), although the water production increases as the inlet feed flow rate increases, the maximum GOR does not show a significant change. And rather, the lower inlet flow rate has achieved the maximum GOR at the lowest module length. These results show that although the increase in the inlet feed flow rate can enhance the water production, it cannot yield a positive effect in terms of GOR and the required effective area.

\subsection{Influence of module width}

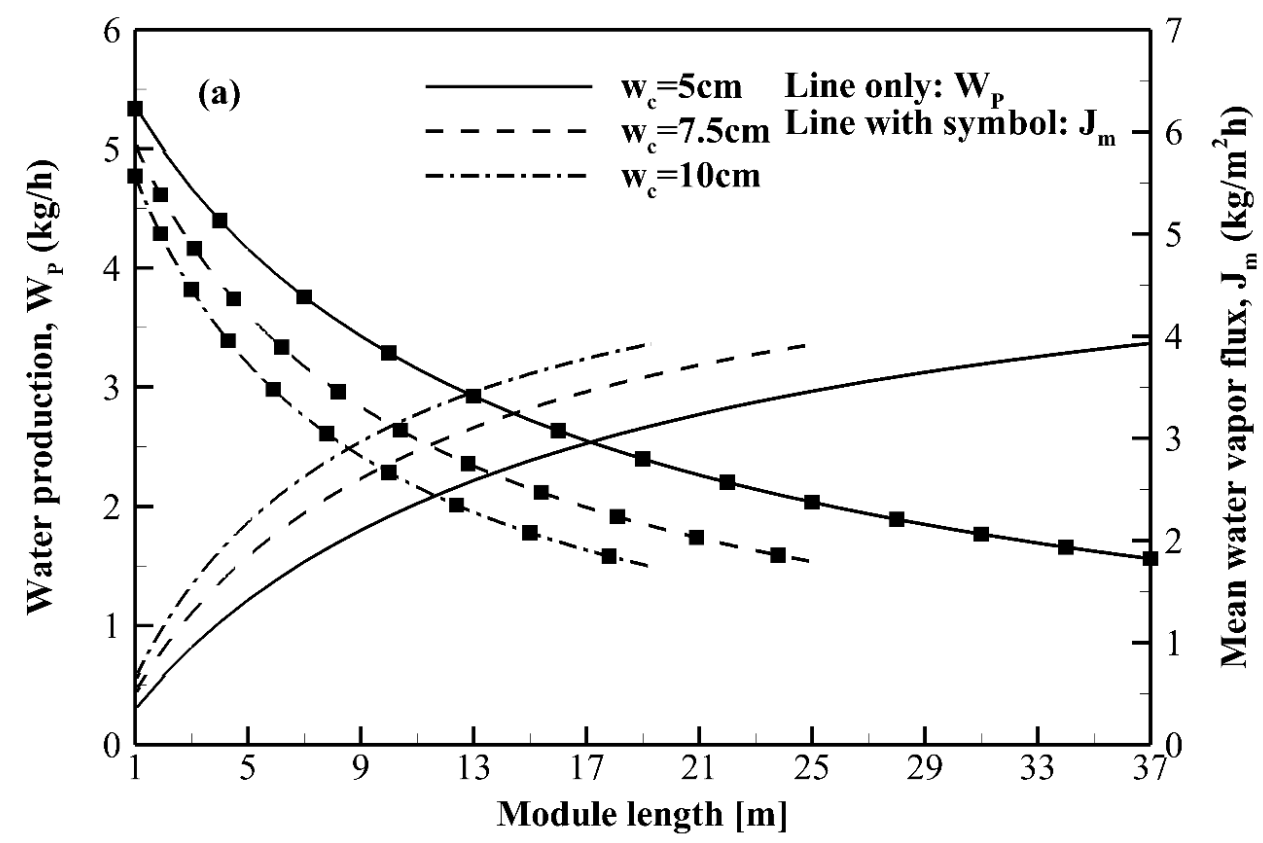




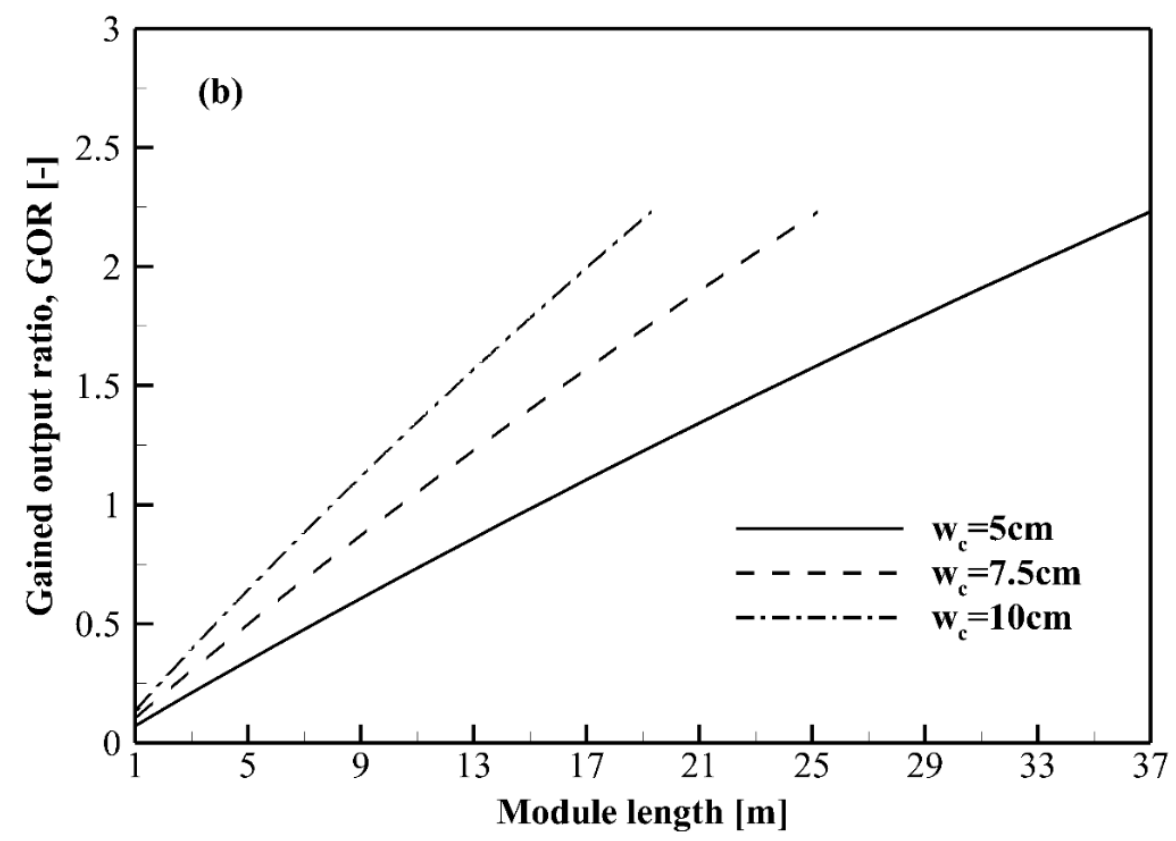

Figure 9. Influence of module width on (a) water production and mean water vapor flux, and (b) $\mathrm{GOR}$ at $70^{\circ} \mathrm{C}$ and $40^{\circ} \mathrm{C}$ (inlet feed and cold temperatures, respectively), $1.5 \mathrm{~kg} / \mathrm{min}$ (inlet feed flow rate), and $42 \mathrm{~g} / \mathrm{kg}$ (feed salinity).

In the MD process, the change of module width affects not only the effective channel area but also feed velocity. Therefore, to estimate the effect of module width on water production, mean water vapor flux and GOR, the simulation studies were conducted at different modules widths of $5 \mathrm{~cm}$, $7.5 \mathrm{~cm}$, and $10 \mathrm{~cm}$ (Fig. 9(a) and (b)). The mean water vapor flux increases as the module width decreases. This is because the small channel area resulting from the narrow module width increases the feed channel velocity and hence decreases temperature polarization and residence time effects. The maximum water production and water recovery are $3.36 \mathrm{~kg} / \mathrm{h}$ and $3.74 \%$, respectively, for a module width of $5 \mathrm{~cm}$. Unlike previous results (section 5.1, 5.2, and 5.3), the increase in the mean water vapor flux did not increase the total water production. This is because the increased ratio of the mean water vapor flux caused by the decrease in the module width is smaller than the decrease ratio in the effective area resulting from a decrease in module width. The maximum GOR does not show a significant change according to the increase in the module width. This is because although the mean water vapor flux increases as the module width decreases, the total thermal energy consumption versus water production through the increased effective area is insignificantly 
changed. In addition, when the module width increases from $0.05 \mathrm{~m}$ to $0.1 \mathrm{~m}$, although the required module length decreases from $37 \mathrm{~m}$ to $19.3 \mathrm{~m}$, the required effective areas increase insignificantly from $1.85 \mathrm{~m}^{2}$ to $1.93 \mathrm{~m}^{2}$.

It clearly shows that the increase in the module width negligibly affects the total required effective area, however, it can prevent the increase in the total required number of modules.

\subsection{Influence of the temperature reduction by using natural cooling system on the GOR}

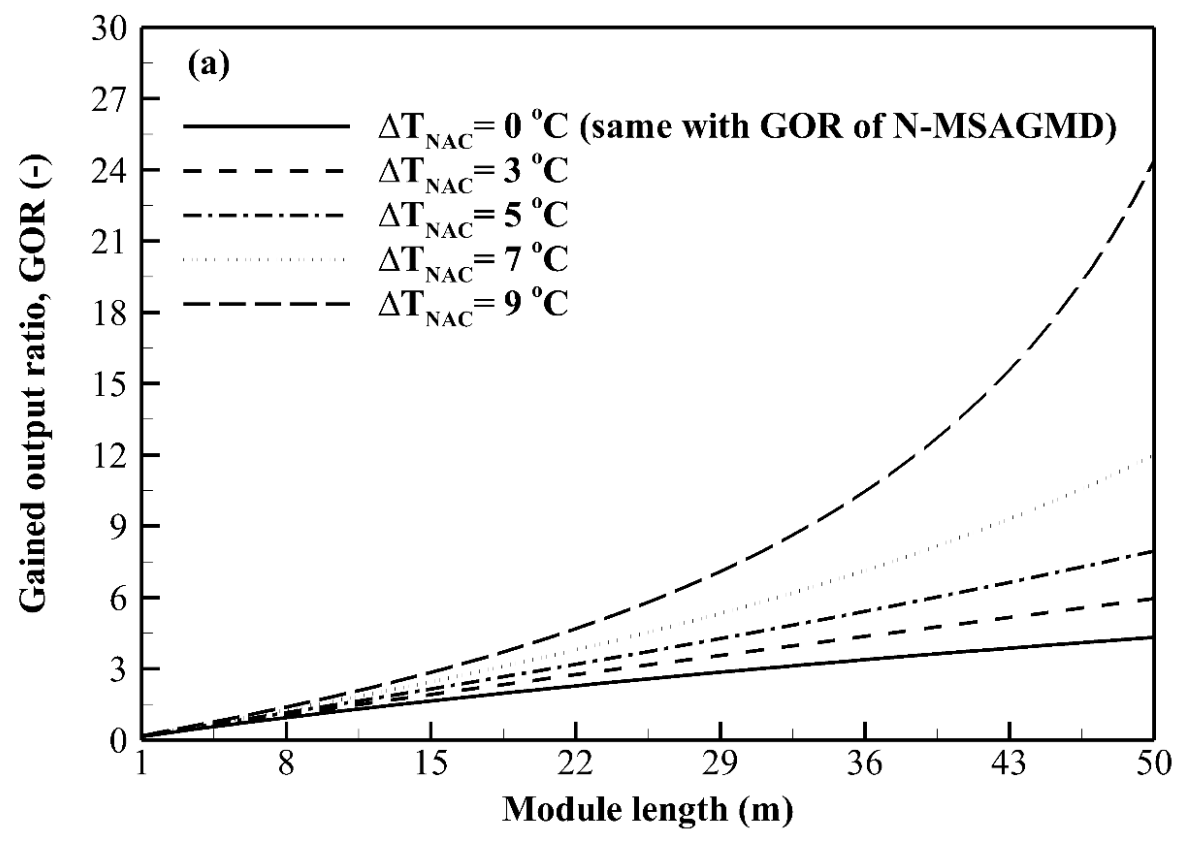




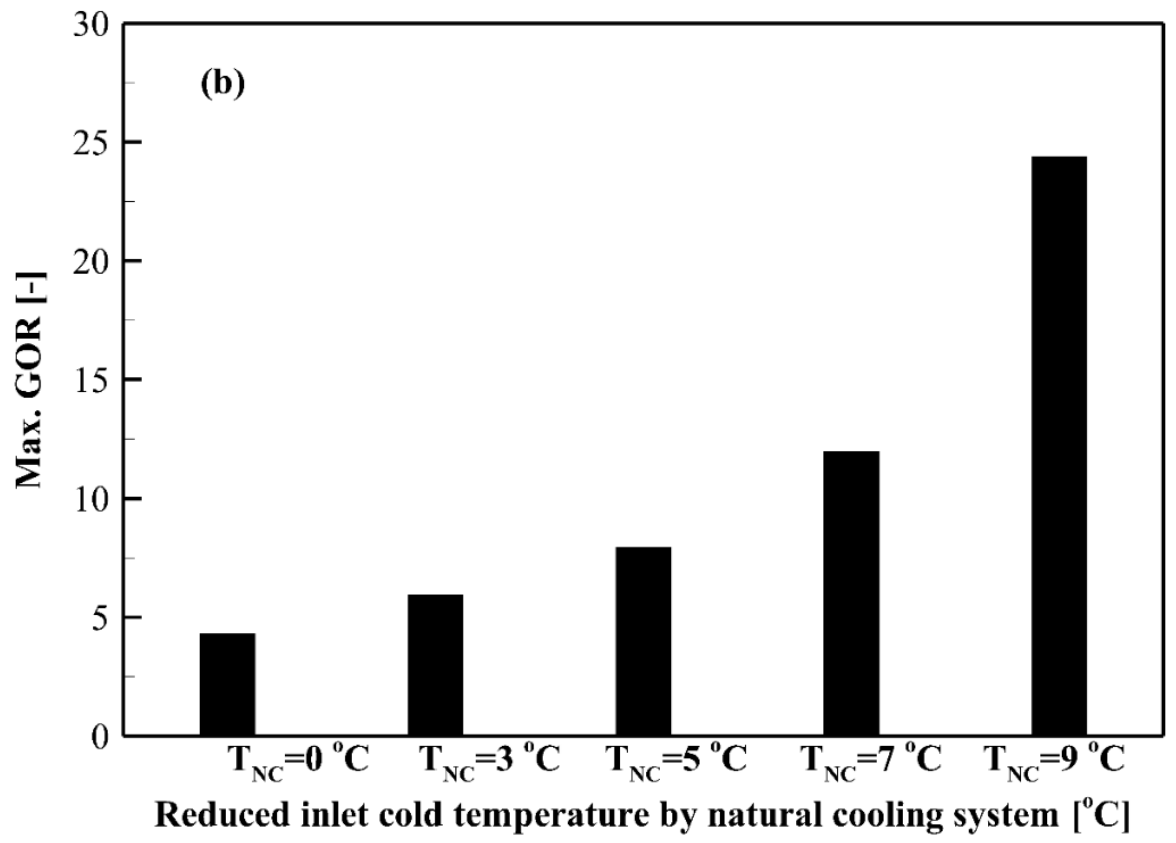

Figure 10. (a) Re-estimated GOR profiles and (b) maximum GOR with reduced outlet feed temperatures by $3^{\circ} \mathrm{C}, 5^{\circ} \mathrm{C}, 7^{\circ} \mathrm{C}$, and $9^{\circ} \mathrm{C}$ to create temperature difference between evaporation and condensation achieved by natural cooling system at $90^{\circ} \mathrm{C}$ and $40^{\circ} \mathrm{C}$ (inlet feed and coolant temperatures, respectively), $1.5 \mathrm{~kg} / \mathrm{min}$ (inlet feed flow rate), and $42 \mathrm{~g} / \mathrm{kg}$ (feed salinity).

In previous sections, the calculated GORs were obtained according to the scenario matrix ((1)(4), see Table 1) considering the forced cooling energy (100\%) to estimate the system's performance. Since the forced cooling heat exchanger is used to cool the coolant liquid, an additional related cooling energy consumption is required, which is not the case when the natural cooling system is used (e.g. atmospheric air temperature, cooling tower, seawater) which doesn't require a significant additional cooling energy (for fans and circulating pumps), and could be even considered negligible [48]. However, the cooling with natural source still needs a large area of cooling surface such as fins heat exchanger. Furthermore, the response of natural cooling system such as cooling tower is low compared to the forced cooling system. Therefore, we propose to use a combined natural/forced cooling medium. To investigate the performance of this system, we reestimated the enhanced GORs by a natural/forced combined cooling system aiming to reduce the forced cooling energy using the atmospheric air temperature of $25^{\circ} \mathrm{C}$ as non-payable cooling energy. In this study, we assume that the cooling tower requires a relatively low electric energy 
consumption $(\sim 0.1 \mathrm{~kW}$ at the full load) for cooling down the brine discharge temperature by maximum $9^{\circ} \mathrm{C}$ compared to the typical energy consumption of chiller. This assumption is based on Lucas et al. [52] reporting the electrical energy consumption of cooling tower $(0.43 \mathrm{~kW})$ for $5^{\circ} \mathrm{C}$ cooling between inlet and outlet at water mass flow rate of $86.4 \mathrm{~kg} / \mathrm{min}$, and dry and wet bulb ambient temperatures of $30^{\circ} \mathrm{C}$ and $27^{\circ} \mathrm{C}$, respectively. Although we need to cool down the brine discharge by maximum $9^{\circ} \mathrm{C}$ which is 1.8 times higher than the reported figure, the flow rate of the current study represents one-ninth of their value. It is ture that if we compare with the same standard the thermal or cooling energy consumption is much higher than the electrical energy consumption.

In summary, at inlet feed temperature and flow rate of $90^{\circ} \mathrm{C}$ and $1.5 \mathrm{~L} / \mathrm{min}$, respectively, the feed temperature decreases from $90^{\circ} \mathrm{C}$ to $50^{\circ} \mathrm{C}$ due to evaporation along the module channel (multi-stage), then the outlet of feed temperature further decreased from $50^{\circ} \mathrm{C}$ to $40^{\circ} \mathrm{C}$ using the combined forced/natural cooling system before its enters the condensers of the AGMD process; and the water production is $6.84 \mathrm{~kg} / \mathrm{h}$. Fig. 10 shows the re-estimated GOR profiles with the reduced outlet feed temperatures $\left(3^{\circ} \mathrm{C}(30 \%), 5^{\circ} \mathrm{C}(50 \%), 7^{\circ} \mathrm{C}(70 \%)\right.$, and $\left.9^{\circ} \mathrm{C}(90 \%)\right)$ achieved by the natural cooling system. As shown in Fig. 11, the maximum GOR increases from 4.32 to 24.4 as the reduced inlet cold temperature by natural cooling system increases from $0^{\circ} \mathrm{C}$ to $9^{\circ} \mathrm{C}$. Here, we assume that the natural cooling energy is negligibly lower than heating energy due to the abundantly available ambient cooling resources such as air or seawater. In addition, the GOR of $\Delta \mathrm{T}_{\mathrm{NC}}=0$ (solid line) which is calculated by considering the fully forced cooling energy can be considered as the performance of the heat recovered in a typical multi-stage AGMD using Eq. (1). The re-estimated GOR profile is significantly increased compared to the GOR profile of typical multi-stage $\operatorname{AGMD}\left(\Delta \mathrm{T}_{\mathrm{NC}}=0\right)$. When $9^{\circ} \mathrm{C}(90 \%)$ of the reduced outlet feed temperature by using the natural cooling system is applied the GOR can reach 24.4 for the same module length. Meanwhile, the GOR of a typical multi-stage AGMD is 3.89 with a similar heating medium having of heating efficiency of $90 \%$. The theoretical possible GOR of the proposed multi-stage AGMD reversal could be 6.28 times higher than that of a typical multi-stage AGMD, which makes the proposed system very attractive for industry implementation.

\section{Conclusions}

This study discussed the possibility of treating hot feeds using a newly proposed multi-stage 
AGMD design consisting of reversing the feed flow of a typical multi-stage AGMD by allowing the inlet hot feed flows inside the evaporation stages and the brine blow down is rejected from the condensation stages, refereed as multi-stage AGMD reversal. The system uses a combined natural/forced cooling system instead of brine heater which is required in the typical design. A rigorous one-dimensional steady-state simulation model was developed to estimate the proposed system performance which was validated with experimental data. The simulation results showed a good agreement with experimental results.

The performances of the proposed system were evaluated at various scenarios and the key findings are as follows:

- As the temperature difference between the feed inlet and coolant outlet, and the inlet flow rate increase, the system performance (water production and GOR) increase. However, this increase comes as an expense for an increase in the required total module length or effective surface area.

- Since the effective area significantly effects the system's performance, the total module length can be properly adjusted by modifying the module width.

- The GOR value of the proposed multi stage AGMD reversal can reach up to 24.4 (6.28 times higher than that of a typical multi stage AGMD) due to the utilization of the nonpayable ambient natural cooling resources.

Furthermore, the discharged brine having $40^{\circ} \mathrm{C}$ is not highly useful for the MD process, although it is higher than the ambient temperature. However, it can be recirculated after reheating to the desired temperature. On the other hand, the discharge brine temperature is set most of the time if not always based on a thorough optimization process between OPEX and CAPEX. Reducing the brine temperature below $40^{\circ} \mathrm{C}$ is expected to result in a significant increase of the capital cost.

\section{Nomenclature}

$C_{m}$ Overall mass transfer coefficient (MTC) across the membrane $\left[\mathrm{kg} /\left(\mathrm{m}^{2} \mathrm{~s} \cdot \mathrm{Pa}\right)\right]$

$C_{K}$ Knudsen diffusion coefficient $\left[\mathrm{kg} /\left(\mathrm{m}^{2} \mathrm{~s} \cdot \mathrm{Pa}\right)\right]$

$C_{M}$ Molecular diffusion coefficient $\left[\mathrm{kg} /\left(\mathrm{m}^{2} \mathrm{~s} \cdot \mathrm{Pa}\right)\right]$

$C_{a}$ MTC of the stagnant air contribution in the air gap area $\left[\mathrm{kg} /\left(\mathrm{m}^{2} \mathrm{~s} \cdot \mathrm{Pa}\right)\right]$ 
$c_{p, f}$ Specific heat of feed solution $[\mathrm{J} /(\mathrm{kg} \cdot \mathrm{K})]$

$c_{p, c}$ Specific heat of the coolant $[\mathrm{J} /(\mathrm{kg} \cdot \mathrm{K})]$

$D$ Binary diffusion coefficient $\left[\mathrm{m}^{2} / \mathrm{s}\right]$

$D_{v / a}$ Diffusion coefficient of the mixture of dry air and water vapor $\left[\mathrm{m}^{2} / \mathrm{s}\right]$

$d_{h, s p}$ Modified hydraulic diameter due to the implementation of spacers [m]

$d z \quad$ Grid size for module length [m]

$h_{c}$ Channel height $[\mathrm{m}]$

$h_{f, c}$ Convection heat transfer coefficients of the feed (f) and cold (c) flows $\left[\mathrm{W} /\left(\mathrm{m}^{2} \cdot \mathrm{K}\right)\right]$

$\Delta H_{g}$ Enthalpy of water vapor $[\mathrm{J} / \mathrm{kg}]$

$J_{o}$ Overall water vapor flux $\left[\mathrm{kg} /\left(\mathrm{m}^{2} \mathrm{~h}\right)\right]$

$J_{m}$ Mean water vapor flux $\left[\mathrm{kg} /\left(\mathrm{m}^{2} \mathrm{~h}\right)\right]$

$k_{\text {air }}$ Thermal conductivity of air $[\mathrm{W} /(\mathrm{m} \cdot \mathrm{K})]$

$k_{m}$ Thermal conductivity of membrane material $[\mathrm{W} /(\mathrm{m} \cdot \mathrm{K})]$

$k_{v / a}$ Thermal conductivity in the gas mixture of air and water vapor $[\mathrm{W} /(\mathrm{m} \cdot \mathrm{K})]$

$k_{\text {cond }}$ Thermal conductivity of the condensation film $[\mathrm{W} /(\mathrm{m} \cdot \mathrm{K})]$

$k_{c p}$ Thermal conductivity of the cooling plate $[\mathrm{W} /(\mathrm{m} \cdot \mathrm{K})]$

$k_{d c}$ Spacer factor [-]

$l \quad$ Module length [m]

$M_{w}$ Molecular weight of water $[\mathrm{g} / \mathrm{mol}]$

$M_{s}$ Molecular weight of salt $[\mathrm{g} / \mathrm{mol}]$

$M_{v, f}$ Molar volume of feed solution $\left[\mathrm{m}^{3} / \mathrm{mol}\right]$

$P_{f} \quad$ Feed bulk pressure $[\mathrm{Pa}]$

$P_{c} \quad$ Coolant bulk pressure $[\mathrm{Pa}]$

$P_{a M}$ Log-mean air pressure at both sides of the membrane $[\mathrm{Pa}]$

$P_{m}$ Mean water vapor pressure inside the membrane [Pa]

$p_{f, m}$ partial vapor pressure on the liquid/vapor interface of feed side $[\mathrm{Pa}]$

$p_{a, m}$ partial vapor pressure on the liquid/vapor interface of air-gap side [Pa]

$p_{m, a}$ Vapor pressure on the air gap side of the membrane [Pa]

$p_{c f, a}$ Vapor pressure on the air gap side of the condensation film [Pa]

$R$ is the ideal gas constant $[\mathrm{J} /(\mathrm{mol} \cdot \mathrm{K})]$

$T_{m}$ Average transmembrane temperature $[\mathrm{K}]$ 
$T_{f, m}$ Feed transmembrane temperature $[\mathrm{K}]$

$T_{f, b}$ Bulk feed temperature $[\mathrm{K}]$

$T_{g}$ Air gap temperature $[\mathrm{K}]$

$T_{a, m}$ Transmembrane temperature of the air gap side $[\mathrm{K}]$

$T_{c f, a}$ Surface temperature of condensation film at the air gap side $[\mathrm{K}]$

$T_{c f, c p}$ Film temperature in contact with the cooling plate $[\mathrm{K}]$

$T_{c p, c f}$ Temperature of the cooling plate surface in the coolant channel [K]

$T_{c, b}$ Bulk coolant temperature [K]

$v_{f}$ Feed velocity $[\mathrm{m} / \mathrm{s}]$

$v_{c} \quad$ Coolant velocity $[\mathrm{m} / \mathrm{s}]$

$V_{\text {fin }}$ Inlet flow rate of the feed side $[\mathrm{kg} / \mathrm{min}]$

$V_{f, \text { out }}$ Outlet flow rate of cold side $[\mathrm{kg} / \mathrm{min}]$

$W_{P}$ Water production $[\mathrm{kg} / \mathrm{h}]$

$w_{c} \quad$ Module width [m]

$x_{f} \quad$ Feed salinity $[\mathrm{g} / \mathrm{kg}]$

$\delta_{g}$ Air gap thickness [m]

$\delta_{\text {cond }}$ Thickness of the condensation film [m]

$\delta_{a}$ Thickness of the air gap [m]

$\delta_{c p}$ Thickness of the cooling plate [m]

$\varepsilon_{s p} \quad$ Spacer porosity [-]

$\mu_{f}$ Dynamic viscosity [Pa $\left.\cdot \mathrm{s}\right]$

$\rho_{f} \quad$ Bulk feed density $\left[\mathrm{kg} / \mathrm{m}^{3}\right]$

$\rho_{c} \quad$ Bulk coolant density $\left[\mathrm{kg} / \mathrm{m}^{3}\right]$

\section{Acknowledgements}

The research reported in this paper was supported by King Abdullah University of Science and Technology (KAUST), Saudi Arabia. The authors acknowledge help, assistance and support from the Water Desalination and Reuse Center (WDRC) staff.

\section{References}

[1] J.-G. Lee, W.-S. Kim, J.-S. Choi, N. Ghaffour, Y.-D. Kim, A novel multi-stage direct contact membrane distillation module: Design, experimental and theoretical approaches, Water Res., 107 (2016) 47-56. 
[2] N. Ghaffour, The challenge of capacity-building strategies and perspectives for desalination for sustainable water use in MENA, Desalination and Water Treatment, 5 (2009) 48-53.

[3] K.L. Hickenbottom, T.Y. Cath, Sustainable operation of membrane distillation for enhancement of mineral recovery from hypersaline solutions, J. Membr. Sci., 454 (2014) 426-435.

[4] L. Martínez, J.M. Rodríguez-Maroto, Membrane thickness reduction effects on direct contact membrane distillation performance, J. Membr. Sci., 312 (2008) 143-156.

[5] K.-J. Lu, J. Zuo, T.-S. Chung, Novel PVDF membranes comprising n-butylamine functionalized graphene oxide for direct contact membrane distillation, J. Membr. Sci., 539 (2017) 34-42.

[6] A. Alkhudhiri, N. Darwish, N. Hilal, Membrane distillation: A comprehensive review, Desalination, 287 (2012) 2-18.

[7] E. Curcio, E. Drioli, Membrane distillation and related operations - a review, Separation and Purification Reviews, 34 (2005) 35-86.

[8] S. Al-Obaidani, E. Curcio, F. Macedonio, G. Di Profio, H. Al-Hinai, E. Drioli, Potential of membrane distillation in seawater desalination: thermal efficiency, sensitivity study and cost estimation, J. Membr. Sci., 323 (2008) 85-98.

[9] H.C. Duong, P. Cooper, B. Nelemans, T.Y. Cath, L.D. Nghiem, Optimising thermal efficiency of direct contact membrane distillation by brine recycling for small-scale seawater desalination, Desalination, 374 (2015) 1-9.

[10] M. El-Bourawi, Z. Ding, R. Ma, M. Khayet, A framework for better understanding membrane distillation separation process, J. Membr. Sci., 285 (2006) 4-29.

[11] L.-H. Cheng, Y.-H. Lin, J. Chen, Enhanced air gap membrane desalination by novel finned tubular membrane modules, J. Membr. Sci., 378 (2011) 398-406.

[12] L.-H. Cheng, P.-C. Wu, J. Chen, Modeling and optimization of hollow fiber DCMD module for desalination, J. Membr. Sci., 318 (2008) 154-166.

[13] M. Khayet, T. Matsuura, Membrane distillation: principles and applications, Elsevier, 2011.

[14] N. Ghaffour, T.M. Missimer, G.L. Amy, Technical review and evaluation of the economics of water desalination: Current and future challenges for better water supply sustainability, Desalination, 309 (2013) 197-207.

[15] T.Y. Cath, V.D. Adams, A.E. Childress, Experimental study of desalination using direct contact membrane distillation: a new approach to flux enhancement, J. Membr. Sci., 228 (2004) 5-16.

[16] F. Laganà, G. Barbieri, E. Drioli, Direct contact membrane distillation: modelling and concentration experiments, J. Membr. Sci., 166 (2000) 1-11.

[17] J. Xu, Y.B. Singh, G.L. Amy, N. Ghaffour, Effect of operating parameters and membrane characteristics on air gap membrane distillation performance for the treatment of highly saline water, J. Membr. Sci., 512 (2016) 73-82.

[18] L. Francis, N. Ghaffour, A.A. Alsaadi, G.L. Amy, Material gap membrane distillation: a new design for water vapor flux enhancement, J. Membr. Sci., 448 (2013) 240-247.

[19] A.S. Alsaadi, L. Francis, H. Maab, G.L. Amy, N. Ghaffour, Evaluation of air gap membrane distillation process running under sub-atmospheric conditions: Experimental and simulation studies, J. Membr. Sci., 489 (2015) 73-80.

[20] A. Alsaadi, N. Ghaffour, J.-D. Li, S. Gray, L. Francis, H. Maab, G. Amy, Modeling of air-gap membrane distillation process: a theoretical and experimental study, J. Membr. Sci., 445 (2013) 53-65.

[21] C.M. Guijt, G.W. Meindersma, T. Reith, A.B.d. Haan, Air gap membrane distillation, Sep. Purif. Technol., 43 (2005) 245-255.

[22] J.-G. Lee, W.-S. Kim, J.-S. Choi, N. Ghaffour, Y.-D. Kim, Dynamic solar-powered multi-stage direct contact membrane distillation system: Concept design, modeling and simulation, Desalination, (2017).

[23] A.E. Khalifa, S.M. Alawad, M.A. Antar, Parallel and series multistage air gap membrane distillation, Desalination, 417 (2017) 69-76.

[24] Y.-D. Kim, K. Thu, S.-H. Choi, Solar-assisted multi-stage vacuum membrane distillation system with heat recovery unit, Desalination, 367 (2015) 161-171. 
[25] J.-G. Lee, W.-S. Kim, Numerical study on multi-stage vacuum membrane distillation with economic evaluation, Desalination, 339 (2014) 54-67.

[26] S. Shim, J. Lee, W. Kim, Performance simulation of a multi-VMD desalination process including the recycle flow, Desalination, 338 (2014) 39-48.

[27] K. Zhao, W. Heinzl, M. Wenzel, S. Büttner, F. Bollen, G. Lange, S. Heinzl, N. Sarda, Experimental study of the memsys vacuum-multi-effect-membrane-distillation (V-MEMD) module, Desalination, 323 (2013) 150-160.

[28] Y.-D. Kim, K. Thu, N. Ghaffour, K.C. Ng, Performance investigation of a solar-assisted direct contact membrane distillation system, J. Membr. Sci., 427 (2013) 345-364.

[29] R. González-Bravo, F. Nápoles-Rivera, J.M. Ponce-Ortega, M. Nyapathi, N. Elsayed, M.M. ElHalwagi, Synthesis of optimal thermal membrane distillation networks, AlChE J., 61 (2015) 448-463.

[30] E. Guillén-Burrieza, J. Blanco, G. Zaragoza, D.-C. Alarcón, P. Palenzuela, M. Ibarra, W. Gernjak, Experimental analysis of an air gap membrane distillation solar desalination pilot system, J. Membr. Sci., 379 (2011) 386-396.

[31] P.A. Hogan, Sudjito, A.G. Fane, G.L. Morrison, Proceedings of the Twelfth International Symposium on Desalination and Water Re-useDesalination by solar heated membrane distillation, Desalination, 81 (1991) 81-90.

[32] S. Lin, N.Y. Yip, M. Elimelech, Direct contact membrane distillation with heat recovery: Thermodynamic insights from module scale modeling, J. Membr. Sci., 453 (2014) 498-515.

[33] H.C. Duong, A.R. Chivas, B. Nelemans, M. Duke, S. Gray, T.Y. Cath, L.D. Nghiem, Treatment of RO brine from CSG produced water by spiral-wound air gap membrane distillation - A pilot study, Desalination, 366 (2015) 121-129.

[34] Z. Ding, L. Liu, M.S. El-Bourawi, R. Ma, Analysis of a solar-powered membrane distillation system, Desalination, 172 (2005) 27-40.

[35] J. Craig, A. Absar, G. Bhat, G. Cadel, M. Hafiz, N. Hakhoo, R. Kashkari, J. Moore, T.E. Ricchiuto, J. Thurow, B. Thusu, Hot springs and the geothermal energy potential of Jammu \& Kashmir State, N.W. Himalaya, India, Earth-Science Reviews, 126 (2013) 156-177.

[36] R. Sarbatly, C.-K. Chiam, Evaluation of geothermal energy in desalination by vacuum membrane distillation, Applied Energy, 112 (2013) 737-746.

[37] J. Bundschuh, N. Ghaffour, H. Mahmoudi, M. Goosen, S. Mushtaq, J. Hoinkis, Low-cost low-enthalpy geothermal heat for freshwater production: Innovative applications using thermal desalination processes, Renewable and Sustainable Energy Reviews, 43 (2015) 196-206.

[38] N. Ghaffour, A. Alsaadi, L. Francis, Vacuumed gap membrane distillation (vagmed) module, multistage vagmed systems, and vagmed processes, in, US Patent App. 15/538,286, 2017.

[39] M.N. Chernyshov, G.W. Meindersma, A.B. de Haan, Comparison of spacers for temperature polarization reduction in air gap membrane distillation, Desalination, 183 (2005) 363-374.

[40] J. Phattaranawik, R. Jiraratananon, A. Fane, Effects of net-type spacers on heat and mass transfer in direct contact membrane distillation and comparison with ultrafiltration studies, J. Membr. Sci., 217 (2003) 193-206.

[41] J. Phattaranawik, R. Jiraratananon, A. Fane, C. Halim, Mass flux enhancement using spacer filled channels in direct contact membrane distillation, J. Membr. Sci., 187 (2001) 193-201.

[42] S. Al-Sharif, M. Albeirutty, A. Cipollina, G. Micale, Modelling flow and heat transfer in spacer-filled membrane distillation channels using open source CFD code, Desalination, 311 (2013) 103-112.

[43] L. Martínez-Díez, M.I. Vázquez-González, F.J. Florido-Díaz, Study of membrane distillation using channel spacers, J. Membr. Sci., 144 (1998) 45-56.

[44] J. Phattaranawik, R. Jiraratananon, A.G. Fane, C. Halim, Mass flux enhancement using spacer filled channels in direct contact membrane distillation, J. Membr. Sci., 187 (2001) 193-201.

[45] S. Soukane, M.W. Naceur, L. Francis, A. Alsaadi, N. Ghaffour, Effect of feed flow pattern on the distribution of permeate fluxes in desalination by direct contact membrane distillation, Desalination, 418 (2017) 43-59. 
[46] J.-G. Lee, W.-S. Kim, Numerical modeling of the vacuum membrane distillation process, Desalination, 331 (2013) 46-55.

[47] J.-G. Lee, Y.-D. Kim, S.-M. Shim, B.-G. Im, W.-S. Kim, Numerical study of a hybrid multi-stage vacuum membrane distillation and pressure-retarded osmosis system, Desalination, 363 (2015) 82-91.

[48] Y.A. Çengel, Heat Transfer: A Practical Approach, McGraw-Hill, 2003.

[49] J.-G. Lee, Y. Jang, L. Fortunato, S. Jeong, S. Lee, T. Leiknes, N. Ghaffour, An advanced online monitoring approach to study the scaling behavior in direct contact membrane distillation, J. Membr. Sci., 546 (2018) 50-60.

[50] J.-G. Lee, Y.-D. Kim, W.-S. Kim, L. Francis, G. Amy, N. Ghaffour, Performance modeling of direct contact membrane distillation (DCMD) seawater desalination process using a commercial composite membrane, J. Membr. Sci., 478 (2015) 85-95.

[51] J.-G. Lee, A.S. Alsaadi, A.M. Karam, L. Francis, S. Soukane, N. Ghaffour, Total water production capacity inversion phenomenon in multi-stage direct contact membrane distillation: A theoretical study, J. Membr. Sci., 544 (2017) 126-134.

[52] M. Lucas, P.J. Martínez, A. Viedma, Experimental study on the thermal performance of a mechanical cooling tower with different drift eliminators, Energy Convers. Manage., 50 (2009) 490-497. 